\title{
EVALUASI PERANCANGAN TRASE JALAN JALUR PUNCAK 2 ALTERNATIF III DESA SUKANAGALIH PACET-PERBATASAN KABUPATEN BOGOR
}

\author{
${ }^{1}$ Suci Pratiwi, ${ }^{2}$ Yudi Sekryadi \\ Program Studi Teknik Sipil Fakultas Teknik Universitas Suryakancana \\ sucip60@gmail.com, yudisekaryadi65@gmail.com
}

\begin{abstract}
Abstrak
Ruas jalan raya puncak merupakan akses jalan yang sering dilewati kendaraan baik itu dari arah Jakarta, Bogor, menuju Cianjur maupun dari arah sebaliknya, namun dengan bertambahnya volume kendaraan yang begitu pesat serta banyaknya wisatawan yang menuju kawasan puncak menyebabkan jalur puncak selalu mengalami kepadatan dan kemacetan kendaraan terutama pada akhir pekan maupun pada setiap momen tertentu. Pembuatan jalan alternatif puncak 2 bertujuan untuk mengatasi kemacetan arus lalu lintas di jalur puncak, serta bisa memacu kunjungan wisatawan dan pertumbuhan ekonomi di kawasan Cianjur dan Bogor. Dalam perencanaan geometrik jalan raya pada penulisan ini mengacu pada Tata Cara Perencanaan Geometrik Jalan Antar Kota tahun 1997 dan untuk perencanaan tebal perkerasan lentur mengacu pada Perencanaan Tebal Perkerasan Lentur Jalan Raya Dengan Analisa Komponen tahun 1989 yang dikeluarkan oleh Dinas Pekerjaan Umum Direktorat Jenderal Bina Marga. Klasifikasi jalan jalur puncak 2 alternatif III merupakan jalan Arteri (Kelas I) dengan panjang jalan $10 \mathrm{~km}$, lebar perkerasan $7 \mathrm{~m}$, kecepatan rencana $60 \mathrm{~km} / \mathrm{jam}$, direncanakan jenis tikungan (Spiral-Circle-Spiral). Perkerasan Jalan jalur puncak 2 alternatif III menggunakan jenis perkerasan lentur berdasarkan volume LHR yang telah didapat, yaitu: Lapis Permukaan $=10 \mathrm{~cm}$, Lapis Pondasi Atas $=20 \mathrm{~cm}$, Lapis Pondasi Bawah $=10 \mathrm{~cm}$. Anggaran Biaya yang dibutuhkan untuk pembangunan Jalan Jalur Puncak 2 alternatif III sebesar Rp.150.978.359.000 .

Kata kunci: Jembatan, Komposit, Beton, Baja
\end{abstract}

\section{PENDAHULUAN}

Jalan merupakan salah satu prasarana transportasi yang sering digunakan, jalan mempunyai peranan penting dalam kehidupan khususnya untuk kelancaran transportasi. Tentunya diharapkan Jalan yang aman, nyaman dan lancar menjadi kebutuhan yang harus terpenuhi demi mencapai cita-cita bersama.

Ruas jalan raya puncak merupakan akses jalan yang sering dilewati kendaraan baik itu dari arah Jakarta, Bogor, menuju Cianjur maupun dari arah sebaliknya, namun dengan bertambahnya volume kendaraan yang begitu pesat serta banyaknya wisatawan yang menuju kawasan puncak menyebabkan jalur puncak selalu mengalami kepadatan dan kemacetan kendaraan terutama pada akhir pekan maupun pada setiap momen tertentu. Kepadatan jalan raya puncak dapat merugikan berbagai pihak tidak terkecuali warga sekitar yang berada di kawasan tersebut karena warga sekitar akan disulitkan untuk beraktivitas dengan adanya kepadatan di daerah tersebut.

Pembuatan jalan alternatif puncak 2 bertujuan untuk mengatasi kemacetan arus lalu lintas di jalur puncak, serta bisa memacu kunjungan wisatawan dan pertumbuhan ekonomi di kawasan Cianjur dan Bogor.

\section{METODOLOGI PENELITIAN}

Obyek penelitian untuk penulisan tugas akhir ini adalah Perancangan trase jalur puncak 2 alternatif III Desa Sukanagalih Pacet-Perbatasan Kabupaten Bogor, dimulai dari STA awal $0+000$ - STA $10+000$, dengan perkiraan panjang penanganan $10,00 \mathrm{~km}$.

Trase jalan Jalur Puneak 2 Alternatif 2 merupakan lokasi yang dijadikan objek penelitian pembangunan jalan baru, dimulai dari Desa Sukanagalih Paeet Cianjur sampai dengan Perbatasan Kabupaten Bogor yang berada di daerah perbukitan. Direneanakan status jalan Nasional, jalan kelas 1 dengan tipe jalan 1 jalur, 2 lajur, 2 arah tak terbagi (2/2 UD). Lebar reneana badan jalan $10,00 \mathrm{~m}$ yang terdiri dari lebar jalur lalu lintas 7,00 $\mathrm{m}$ dan lebar bahu jalan bagian kiri dan kanan masing-masing 1,50 $\mathrm{m}$ dengan panjang jalan Adapun Peta Lokasi Trase Jalur Puneak 2 Alternatif 2 dan profil ketinggian permukaan tanah terdapat pada Gambar 1 dan Gambar 2 berikut: 


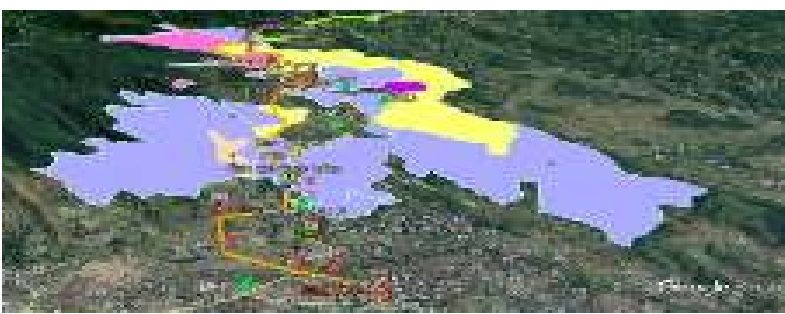

Gambar 1. Peta Trase Jalur Puneak 2 Alternatif 3

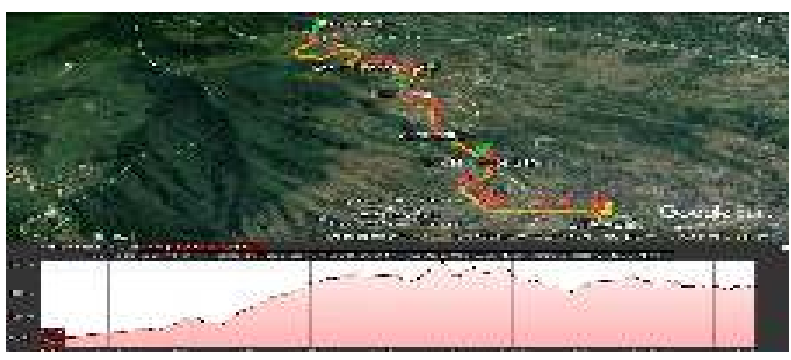

Gambar 2 Profil Ketinggian Permukaan Tanah 4 Sumber: Dinas PUPR Kabupaten

Dalam perancangan trase jalan jalur puncak 2 alternatif 2 ini terdapat alur dalam penyusunan ini, yaitu sebagai berikut

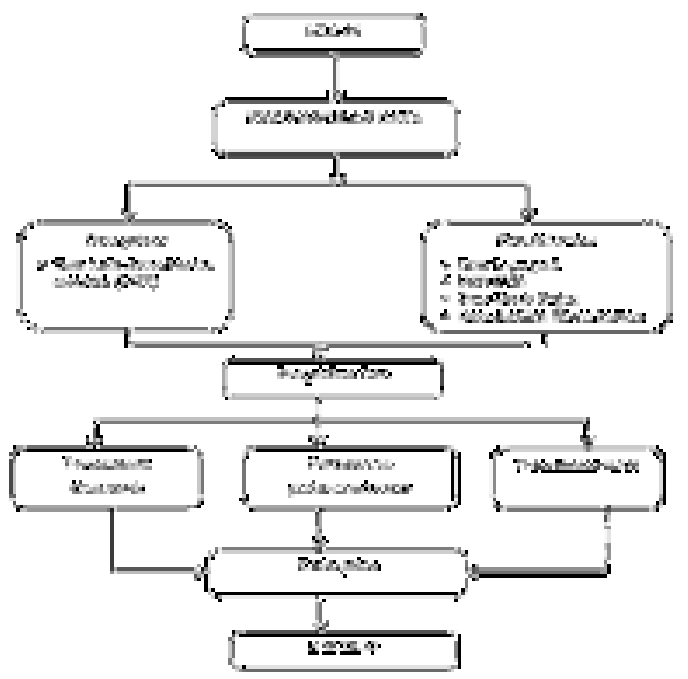

Gambar 3. Alur Metodologi Penelitian

\section{Pengumpulan Data}

Dalam menyelesaikan tugas akhir ini, dibutuhkan beberapa data pendukung untuk mendapatkan hasil perencanaan yang optimal. Data-data yang dibutuhkan tersebut dibagi menjadi data primer dan data sekunder yang akan dijelaskan di bawah ini:

\section{a. Data Primer}

Pada pendekatan ini, penulis melakukan pengumpulan data yang diperoleh dari hasil survei dan pengamatan di lapangan serta mengadakan Tanya jawab langsung kepada pihak yang terkait.

1. Data lalu lintas harian rata-rata (LHR) digunakan untuk merencanakan tebal perkerasan jalan dengan adanya tingkat pertumbuhan kendaraan rata-rata per tahun. Adapun klasifikasi kendaraan yang dikelompokkan yaitu :

a) Kendaraan Ringan (LV) Kendaraan bermotor ber as dua dengan 4 roda dan dengan jarak as 2,0 - 3,0 $\mathrm{m}$ (meliputi: mobil penumpang, oplet, mikro bis, dan pick-up sesuai sistem klasifikasi Bina Marga).

b) Kendaraan Berat Menengah (MHV) Kendaraan bermotor ber as dua dengan 4 roda dengan jarak 3,5 - 5,0 meter (termasuk bis kecil, truk dua as, sesuai sistem klasifikasi Bina Marga).

c) Sepeda Motor (MC) Kendaraan bermotor dengan 2 atau 3 roda (meliputi sepeda motor dan kendaraan roda 3 sesuai sistem klasifikasi Bina Marga).

\section{b. Data Sekunder}

Data sekunder merupakan sumber data yang diperoleh dari pihak lain, baik secara langsung maupun tidak langsung. Data yang diperoleh penulis adalah sebagai berikut:

1. Data topografi tugas akhir penulis dapatkan dari Bidang Pembangunan Jalan dan Jembatan Dinas PUPR Kabupaten Cianjur

2. Data CBR Tanah

Uji CBR merupakan standar tes untuk mengetahui kekuatan tanah. Kekuatan tanah dasar seperti yang ada di lapangan seperti nilai CBR tergantung pada kondisi pada saat pelaksanaan dan selama pelayanan operasi berlangsung.

3. Data Curah Hujan

Data curah hujan tahunan maksimum, sangat diperlukan guna untuk menghitung tinggi hujan rencana dan periode ulang.

4. Data Analisa Harga Satuan

Data Analisis Harga satuan adalah sebagai tuntunan/pedoman pada saat akan merencanakan anggaran biaya yang terdapat angka-angka yang menjelaskan tenaga, biaya, dan jumlah material per satuan pekerjaan.

\section{Pengolahan Data}

Pengolahan data ini ditunjukkan untuk mendapatkan hasil perencanaan dari data-data yang telah dikumpulkan. Hasil perencanaan yang 
dihasilkan antara lain adalah tebal perkerasan jalan raya, jarak pandang, Alinemen horizontal dan alinemen vertikal. Untuk mendapatkan tebal perkerasan yang direncanakan, maka digunakan Tata Cara Perencanaan Tebal Perkerasan Lentur Jalan Raya dengan Metode Analisa Komponen SNI 1732-1989-F. Untuk alternative geometrik jalan raya (jarak pandang, alinemen horizontal dan alinemen vertikal) digunakan Tata Cara Perencanaan Geometrik Jalan Antar Kota No. 038/TBM/1997.

\section{PEMBAHASAN}

\section{a. Alinemen Horizontal}

Peta yang dipakai Kabupaten Cianjur diperoleh dari citra satelit

Kelas I (Arteri)

$\begin{array}{ll}\mathrm{Vr} & =60 \mathrm{~km} / \mathrm{jam} \\ \mathrm{e} \max & =10 \% \\ \text { e normal } & =2 \%\end{array}$

Lebar perkerasan $=2 \times 3,5 \mathrm{~m}$

F_max $=0,192-(0,00065 \times \mathrm{V}$ r $)$

F $\max =0,192-(0,00065 \times 60)$

F_max $=0,153$

$R_{\text {min }}=\frac{V R^{2}}{127\left(e_{\max }+F_{\max }\right)}$

$R_{\text {min }}=\frac{60^{2}}{127(0,1+0,153)}$

$R_{\min }=112 \mathrm{~m}$

$D_{\text {max }}=\frac{181913,53 x\left(e_{\max }+F_{\max }\right)}{V R^{2}}$

$D_{\text {max }}=\frac{181913,53 \times(0,1+0,153)}{60^{2}}$

$D_{\max }=12,78^{\circ}$

\section{b. Tikungan $\mathbf{P I}_{8}$}

Direncanakan $\mathrm{Rc}=130 \mathrm{~m}>R_{\min }=112 \mathrm{~m}$

1. Perhitungan lengkung peralihan (1s)

a. Berdasarkan dari tabel dengan $\mathrm{Vr}=60$ $\mathrm{km} / \mathrm{jam}$ didapat : Ls min $=60 \mathrm{~m}, e_{\text {penuh }} 0.1$ $=10 \%$

b. Berdasarkan waktu tempuh maksimum di lengkung peralihan

$L s=\frac{V r}{3.6} T$

$T=3$ detik (ditetapkan)

$L s=\frac{60}{3.6} \times 3=50 \mathrm{~m}$

c. Berdasarkan tingkat pencapaian perubahan kelandaian

$L s=\frac{\left(e_{m}-e_{n}\right)}{3.6 r_{e}} V r$

$$
L s=\frac{(10 \%-2 \%)}{3.6 \times 0.035} \times 6=38.10 \mathrm{~m}
$$

d. Berdasarkan antisipasi gaya sentrifugal

$$
\begin{aligned}
L s= & 0,022 \times \frac{V r^{3}}{R_{\text {desain }} \times C} \\
& -2,727 \times \frac{\operatorname{Vr} x e_{\text {max }}}{C} \\
L s= & 0,022 \times-2,727 \times \frac{60 \times 0,1}{2} \\
L s= & 14.23 \mathrm{~m}
\end{aligned}
$$

Maka, diambil Ls terbesar yaitu Ls $=60 \mathrm{~m}$

2. Penentuan tipe lengkung horizontal

Penentuan tipe lengkung horizontal Tikungan direncanakan menggunakan (SCS).

Input data :

$$
\begin{array}{ll}
\beta & =67^{\circ} \\
\mathrm{Vr} & =60 \mathrm{~km} / \mathrm{jam} \\
e_{\text {max }} & =10 \% \\
e_{\text {normal }}=2 \% & \\
\mathrm{Rc} & =130 \mathrm{~m}
\end{array}
$$

a. Menghitung sudut lengkung spiral $\left(\theta_{s}\right)$

$$
\begin{aligned}
\theta_{s} & =\frac{90 L s}{\pi R c} \\
\theta_{s} & =\frac{90 \times 60}{3,14 \times 130} \\
\theta_{s} & =13,22^{\circ}
\end{aligned}
$$

b. Menghitung sudut lengkung spiral $\left(\theta_{c}\right)$

$\theta_{c}=\beta-2 \times \theta_{s}$

$\theta_{c}=67-2 \times 13,22$

$\theta_{c}=40,56^{\circ}$

c. Menghitung panjang busur lingkaran (Lc)

$$
\begin{aligned}
L c & =\frac{\theta_{c}}{360} \times 2 \times \pi \times R c \\
L c & =\frac{40,56}{360} \times 2 \times \pi \times 130 \\
L c & =91,98 \mathrm{~m}
\end{aligned}
$$

Syarat tikungan SCS : Lc $>20 \mathrm{~m}$

$91,98 \mathrm{~m}>20 \mathrm{~m} . . . \mathrm{OK}$

d. Menghitung pergeseran tangen terhadap spiral (p) dan absis dari $p$ pada garis tangen spiral (k)

$$
\begin{aligned}
& p=\frac{L s^{2}}{6 \times R c}-R c\left(1-\cos \theta_{s}\right) \\
& p=\frac{60^{2}}{6 \times 130}-130(1-\cos 13,22) \\
& p=1,17 \mathrm{~m}
\end{aligned}
$$

Syarat tikungan SCS : $\mathrm{p}>0,25$

$$
1,17>0,25 \ldots \mathrm{OK}
$$

$k=L s-\frac{L s^{3}}{40 \times R c^{2}}-R c x \sin \theta_{s}$ 
$k=60-\frac{60^{3}}{40 \times 130^{2}}-130 \times \sin 13,22$ $k=29,95 \mathrm{~m}$

e. Menghitung jarak antar perpotongan bagian lurus (Ts)

$T s=(R c+p) \tan 0,5 \beta+k$

$T s=(130+1,17) \tan 0,5 \times 67+29,95$

$T s=116,78 \mathrm{~m}$

f. Menghitung jarak antara perpotongan bagian lurus dengan busur lingkaran (Es)

$$
\begin{aligned}
E S & =\frac{(R c+p)}{\left(\operatorname{Cos} \frac{1}{2} \beta\right)}-R c \\
& =\frac{(130+1,17)}{\left(\operatorname{Cos} \frac{1}{2} 67\right)}-130 \\
& =27,2 \mathrm{~m}
\end{aligned}
$$

g. Menghitung panjang busur keseluruhan $\left(L_{\text {tot }}\right)$

$$
\begin{aligned}
L_{t o t}=2 L s+L c & =2 \times 60+91,98 \\
& =211,98 \mathrm{~m}
\end{aligned}
$$

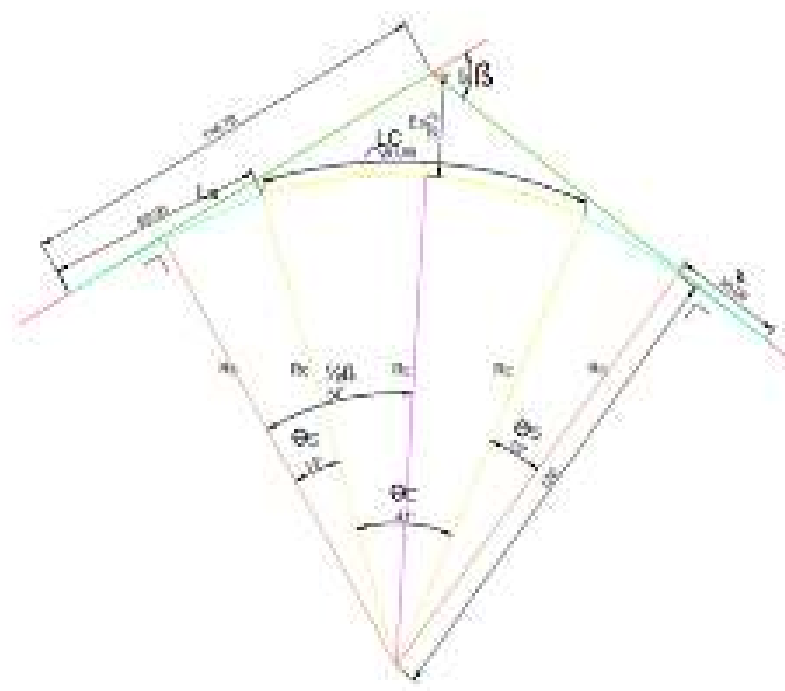

Gambar 4 Tikungan Spiral Circle Spiral $\mathrm{PI}_{8}$

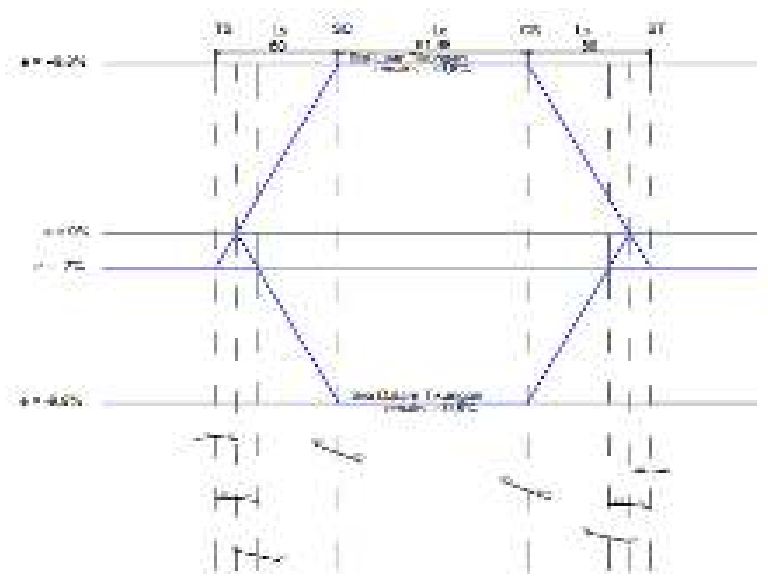

Gambar 4. Diagram Superelevasi

Tikungan Spiral-Circle-Spiral (PI3)

c. Perhitungan Pelebaran Perkerasan

Jalan kelas I ( arteri ) muatan sumbu terberat 10 ton sehingga direncanakan kendaraan terberat yang melintas adalah kendaraan berat.

Perhitungan:

$$
\begin{aligned}
& \text { 1. } b^{\prime \prime}=130-\left(\sqrt{R^{2}-P^{2}}\right) \\
& =130-\left(\sqrt{130^{2}-18,9^{2}}\right) \\
& =1,38 \mathrm{~m} \\
& b^{\prime}=2,6+1,38 \\
& \text { 2. } T_{d}=\sqrt{R^{2}+A(2 P+A)}-R \\
& =\sqrt{130^{2}+1,2(2 \times 18,9+1,2)} \\
& -130 \\
& =0.18 \mathrm{~m} \\
& \text { 3. } Z=0,105 \times \frac{V r}{\sqrt{R C}} \\
& =0,105 \times \frac{60}{\sqrt{130}} \\
& =0.55 \mathrm{~m} \\
& \text { 4. } B=n\left(b^{\prime} c\right)+(n-1) T_{d}+Z \\
& =2(3,98+0.9)+(2-1) 0.18 \\
& +0.55 \\
& =10,49 \mathrm{~m}>7 \mathrm{~m} \\
& \mathrm{~W}=\mathrm{B}-\mathrm{L} \\
& =10,49-7 \\
& =3,5 \mathrm{~m}
\end{aligned}
$$

Karena $\mathrm{B}>\mathrm{W}$ maka diperlukan lebar perkerasan pada tikungan $\mathrm{PI}_{8}$ sebesar $3,8 \mathrm{~m}$.

d. Penghitungan kebebasan samping pada $\mathbf{P I}_{8}$

Data-data:

$$
\begin{aligned}
& \mathrm{Vr}=60 \mathrm{~km} / \mathrm{jam} \\
& \mathrm{Rc}=130 \mathrm{~m} \\
& \mathrm{~W}=2 \times 3,5 \mathrm{~m}=7 \mathrm{~m} \\
& \mathrm{Lc}=91,98 \mathrm{~m}
\end{aligned}
$$

- Jarak pandang henti (Jh) $=75 \mathrm{~m}$

- Jarak pandang menyiap (Jd) $=350 \mathrm{~m}$

- Lebar pengawasan minimal $=30 \mathrm{~m}$

Perhitungan :

$$
\begin{aligned}
\mathrm{R}^{\prime} & =\mathrm{Rc}-1 / 2 \mathrm{~W} \\
& =130-1 / 27 \\
& =126,5 \mathrm{~m} \\
\mathrm{Lt} & =\mathrm{Lc}+(2 \times \mathrm{Ls}) \\
& =91,98+(2 \times 60) \\
& =211,98 \mathrm{~m}
\end{aligned}
$$

a. Jarak pandang henti berdasarkan TPGJAK

1997: 


$$
\begin{aligned}
\mathrm{Jh} & =0,694 \mathrm{Vr}+0,004\left[\mathrm{Vr}^{2} /(f p)\right] \\
& =0,694 \times 60+0,004 \times\left[60^{2} /(0,50)\right] \\
& =70,44 \mathrm{~m}
\end{aligned}
$$

b. Jarak pandang henti berdasarkan Shirley

L.hendarsin

$f p=$ Koefisien gesek memanjang menurut Bina

Marga, $f \mathrm{p}=0.35-0.55$

$$
\begin{aligned}
\mathrm{Jh} & =0,278 \mathrm{~V} \cdot \mathrm{t}+\frac{V^{2}}{254 f} \\
& =0,27860 \times 2,5+\frac{60^{2}}{254 \times 0,50} \\
& =70,04 \mathrm{~m}
\end{aligned}
$$

Diambil $\mathrm{Jh}$ terbesar $=70,04 \mathrm{~m}$

c. Berdasarkan jarak pandang menyiap

$$
\begin{aligned}
\mathrm{Jd} & =\mathrm{d}_{1}+\mathrm{d}_{2}+\mathrm{d}_{3}+\mathrm{d}_{4} \\
\mathrm{~d}_{1} & =0,278 \times T_{1} \times\left(V_{R}-\mathrm{m}+\frac{a \times T_{1}}{2}\right) \\
\mathrm{d}_{2} & =0,278 \times V_{R} \times T_{2} \\
\mathrm{~d}_{3} & =\text { antara } 30-100 \mathrm{~m} \\
\mathrm{~d}_{4} & =2 / 3 \times \mathrm{d}_{2}
\end{aligned}
$$

Dimana :

$\mathrm{T}_{1}=$ Waktu dalam (detik), $\infty 2.12+0,026 \times \mathrm{Vr}$

$\mathrm{T}_{2}=$ Waktu kendaraan berada di jalur lawan, (detik) 6,56+0,048xVr

$\mathrm{A}=$ Percepatan rata-rata $\mathrm{km} / \mathrm{jam} / \mathrm{dtk}$, $(\mathrm{km} / \mathrm{jam} /$ detik),2,052+0,0036xVr

$\mathrm{m}$ = perbedaan kecepatan dari kendaraan yang menyiap dan kendaraan yang di siap, (biasanya diambil 10-15 km/jam)

$$
\begin{aligned}
\mathrm{T}_{1} & =2.12+0,026 \times 60 \\
& =3,7 \\
\mathrm{~T}_{2} & =6,56+0,048 \times 60 \\
& =9,44 \\
\mathrm{~A} & =2,052+0,003 \times 60 \\
& =2,3 \\
\mathrm{M} & =15 \\
\mathrm{~d}_{1} & =0,278 \times T_{1} \times\left(V_{R}-\mathrm{m}+\frac{a \times T_{1}}{2}\right) \\
& =0,278 \times 3,7 \times\left(60-15+\frac{2,3 \times 3,7}{2}\right) \\
& =50,66 \mathrm{~m} \\
\mathrm{~d}_{2} & =0,278 \times V_{R} \times T_{2} \\
& =0,278 \times 60 \times 9,44 \\
& =157,46 \mathrm{~m} \\
\mathrm{~d}_{3} & =a n t a r a 30-100 \mathrm{~m} \\
& =30 \mathrm{~m} \\
\mathrm{~d}_{4} & =2 / 3 \times \mathrm{d}_{2} \\
& =2 / 3 \times 157,46 \\
\mathrm{Jd} & =\mathrm{d}_{1}+\mathrm{d}_{2}+\mathrm{d}_{3}+\mathrm{d}_{4} \\
\mathrm{Jd} & =50,66+157,46+30+104,97 \\
\mathrm{Jd} & =343,09 \mathrm{~m}^{2}
\end{aligned}
$$

Jd terbesar diambil $=343,09$

Kebebasan samping yang tersedia

$(\mathrm{mo})=1 / 2($ lebar pengawasan minimal $-\mathrm{w})$

$$
=1 / 2(30-7)
$$

$$
=11,5 \mathrm{~m}
$$

Secara analitis :

- Berdasarkan jarak pandang henti :

$\mathrm{Jh}=70,44 \mathrm{~m}$

$\mathrm{Lt}=211,98 \mathrm{~m} \mathrm{Jh}<\mathrm{Lt}$

$\mathrm{E}=\mathrm{R}^{\prime} \times\left(1-\cos \mathrm{x}\left(\frac{28,65 \times \mathrm{Jh})}{R^{\prime}}\right)\right.$

$\mathrm{E}=126,5 \times\left(1-\cos \times\left(\frac{28,65 \times 70,44)}{126,5}\right)\right.$

$\mathrm{E}=4,87 \mathrm{~m}$

- Berdasarkan jarak pandang menyiap :

$\mathrm{Jd}=343,09$

$\mathrm{Lt} \quad=211,98 \quad \mathrm{Jd}<\mathrm{Lt}$

$\mathrm{E}=\mathrm{R}^{\prime} \mathrm{x}\left(1-\cos \mathrm{x}\left(\frac{28,65 \times J d)}{R^{\prime}}\right)+\frac{(J d-L t)}{2} \mathrm{x} \sin \right.$ $\left(\frac{28,65 \times \mathrm{Jd})}{R^{\prime}}\right)$

$$
=126,5 \times\left(1-\cos \times\left(\frac{28,65 \times 343,09)}{126,5}\right)+\right.
$$$$
\frac{(343,09-211,98)}{2} \times \sin \left(\frac{28,65 \times 343)}{126,5}\right)
$$

$=154,42 \mathrm{~m}$

Rekapitulasi hitungan :

1. Kebebasan samping henti $=4,87 \mathrm{~m}$

2. Kebebasan samping menyiap $=154,42 \mathrm{~m}$

3. Kebebasan samping tersedia $=11,52 \mathrm{~m}$

4. Kebebasan samping berdasarkan jarak pandang henti 4,87 $\mathrm{m}<11,5$ tidak aman

5. Kebebasan samping berdasarkan jarak pandang menyiap 154,42 $\mathrm{m}>11,5 \mathrm{~m}$ sehingga sebelum memasuki tikungan $\mathrm{PI}_{1}$ perlu dipasang rambu dilarang menyiap.

\section{e. Tikungan $\mathbf{P I}_{\mathbf{1 2}}$}

Direncanakan $\mathrm{Rc}=179 \mathrm{~m}>R_{\min }=112 \mathrm{~m}(\mathrm{Rc}$ berdasarkan tabel 2.7)

1. Perhitungan lengkung peralihan (ls)

a. Berdasarkan waktu tempuh maksimum di lengkung peralihan

$$
\begin{gathered}
L s=\frac{V r}{3.6} T \\
T=3 \operatorname{detik}(\text { ditetapkan }) \\
L s=\frac{60}{3.6} \times 3=50 \mathrm{~m}
\end{gathered}
$$

b. Berdasarkan tingkat pencapaian perubahan kelandaian

$$
L s=\frac{\left(e_{m}-e_{n}\right)}{3.6 r_{e}} V r
$$




$$
\begin{gathered}
L s=\frac{(10 \%-2 \%)}{3.6 \times 0.035} \times 60=38.10 \mathrm{~m} \\
\text { c. Berdasarkan antisipasi gaya } \\
\begin{array}{c}
\text { sentrifugal } \\
L s=0,022 \times \frac{V r^{3}}{R_{\text {desain }} \times C}-2,727 \times \frac{V r \times e_{\text {max }}}{C}
\end{array} \\
L s=0,022 \times \frac{60^{3}}{179 \times 2}-2,727 \times \frac{60 \times 0,1}{2} \\
=39,641 \mathrm{~m}
\end{gathered}
$$

Maka, diambil Ls terbesar yaitu Ls $=50 \mathrm{~m}$

2. Penentuan tipe lengkung horizontal Tikungan direncanakan menggunakan (SCS) data :

$$
\begin{array}{ll}
\beta & =64^{\circ} \\
\mathrm{Vr} & =60 \mathrm{~km} / \mathrm{jam} \\
e_{\text {max }} & =10 \% \\
e_{\text {normal }} & =2 \% \\
\mathrm{Rc} & =179 \mathrm{~m}
\end{array}
$$

a. Menghitung sudut lengkung spiral $\left(\theta_{S}\right)$

$$
\begin{gathered}
\theta_{s}=\frac{90 L s}{\pi R c} \\
\theta_{s}=\frac{90 \times 50}{3,14 \times 179} \\
\theta_{s}=8^{\circ}
\end{gathered}
$$

b. Menghitung sudut lengkung spiral $\left(\theta_{c}\right)$

$$
\begin{gathered}
\theta_{c}=\beta-2 \times \theta_{s} \\
\theta_{c}=64-2 \times 8 \\
\theta_{c}=48^{\circ}
\end{gathered}
$$

c. Menghitung panjang busur lingkaran (Lc)

$\mathrm{Lc}=\theta \mathrm{c} / 360 \times 2 \times \pi \times \mathrm{Rc}$

$\mathrm{Lc}=48 / 360 \times 2 \times \pi \times 179$

$\mathrm{Lc}=149,88 \mathrm{~m}$

Syarat tikungan SCS : Lc $>20 \mathrm{~m}$

$149,88 \mathrm{~m}>20 \mathrm{~m}$...OK

3. Menghitung pergeseran tangen terhadap spiral (p) dan absis dari $\mathrm{p}$ pada garis tangen spiral (k)

$\mathrm{p}=\llbracket \mathrm{Ls} \rrbracket \wedge 2 /(6 \mathrm{x} \mathrm{Rc})-\operatorname{Rc}\left(1-\cos \llbracket \theta_{-} \mathrm{s} \rrbracket\right)$

$\mathrm{p}=\llbracket 50 \rrbracket \wedge 2 /(6 \times 179)-179(1-\cos 8)$

$\mathrm{p}=0,58 \mathrm{~m}$

Syarat tikungan SCS : $\mathrm{p}>0,25$

$0,58>0,25 \ldots \mathrm{OK}$

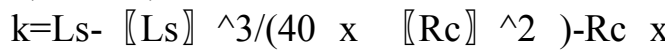
$\sin \llbracket \theta \mathrm{s} \rrbracket$

$\mathrm{k}=50-\llbracket 50 \rrbracket \wedge 3 /(40 \mathrm{x}$ 『179】^2 $)-179 \mathrm{x}$

$\sin 8$

$\mathrm{k}=24,99$

4. Menghitung jarak antar perpotongan bagian lurus (Ts)
$\mathrm{Ts}=(\mathrm{Rc}+\mathrm{p})$ tan $\llbracket 0,5 \beta+\mathrm{k} \rrbracket$

$\mathrm{Ts}=(179+0,58)$ tan $\llbracket 0,5 \times 64+24,99 \rrbracket$

$\mathrm{Ts}_{\mathrm{s}}=137,20 \mathrm{~m}$

5. Menghitung jarak antara perpotongan bagian lurus dengan busur lingkaran (Es)

$E s=((\operatorname{Rc}+p)) /((\operatorname{Cos} 1 / 2 \beta))-$

$\mathrm{Rc}=((179+0,58)) /((\operatorname{Cos} 1 / 264))-179$ $=32,75 \mathrm{~m}$

6. Menghitung panjang busur keseluruhan (L_tot)

L_tot $=2 \mathrm{Ls}+\mathrm{Lc}=2 \times 50+149,88=249,88 \mathrm{~m}$

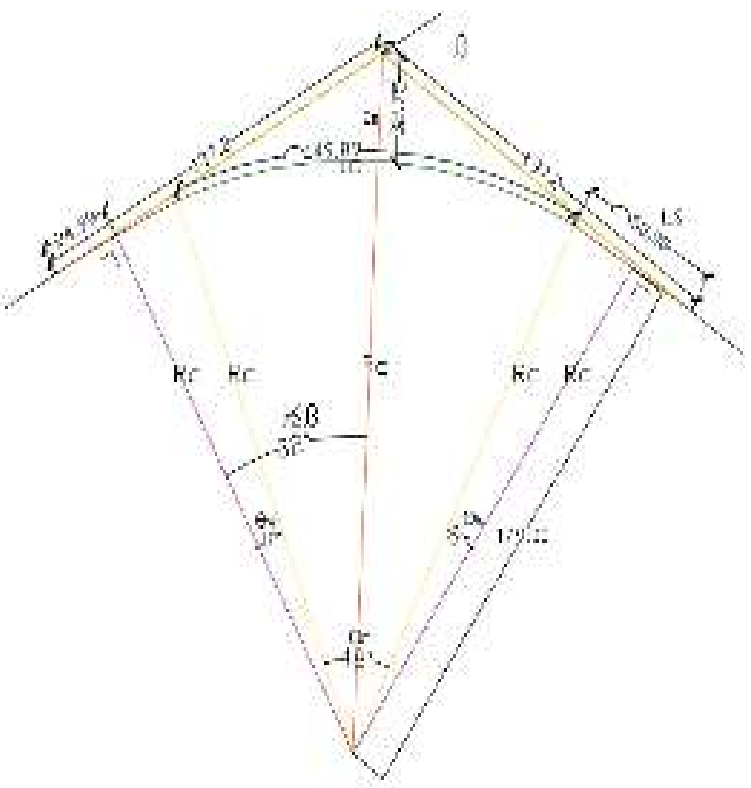

Gambar 5 Tikungan Spiral Circle Spiral $\mathrm{PI}_{12}$

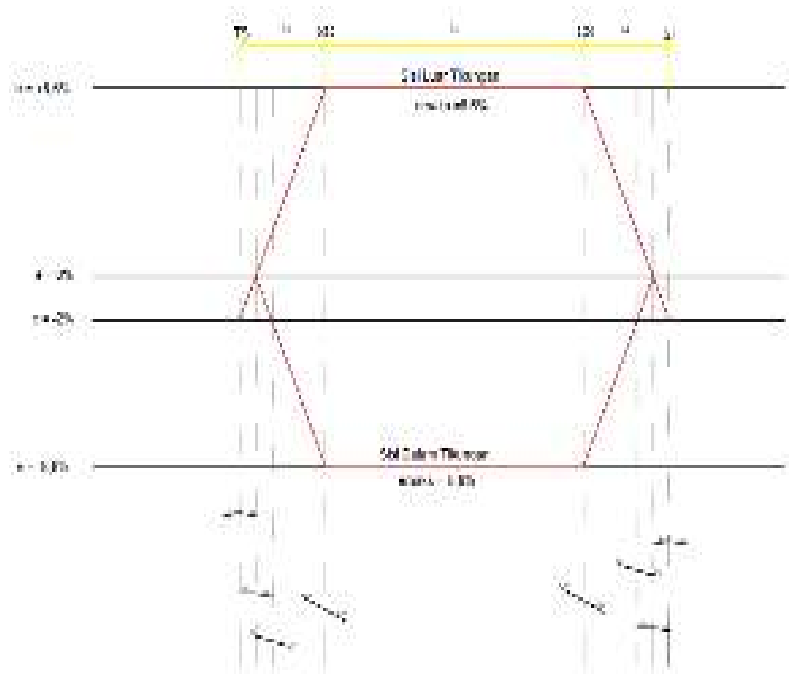

Gambar 6 Diagram superelevasi tikungan $\mathrm{PI}_{12}$ 


$$
=0,13 \mathrm{~m}
$$

\section{f. Perhitungan Pelebaran Perkerasan}

Jalan kelas I ( arteri ) muatan sumbu terberat 10 ton sehingga direncanakan kendaraan terberat yang melintas adalah kendaraan berat.

Rumus:

$$
\begin{aligned}
& B=n\left(b^{\prime}+c\right)+(n-1) T_{d}+Z \\
& b^{\prime}=\left(R c-\sqrt{R^{2}-P^{2}}\right) \\
& T_{d}=\sqrt{R^{2}+A(2 P+A)}-R \\
& Z=\frac{0.105 V_{R}}{\sqrt{R c}}
\end{aligned}
$$

Dimana:

$\mathrm{B}=$ lebar perkerasan pada tikungan (7 $\mathrm{m})$

$\mathrm{b}=$ lebar lintasan kendaraan berat pada ruas jalan $(2,6 \mathrm{~m})$

$\mathrm{n} \quad=$ jumlah lajur lalu lintas (2)

$\mathrm{T}_{\mathrm{d}}=$ lebar melintang akibat tonjolan depan

$\mathrm{Z}=$ lebar tambahan akibat kelainan dalam mengemudi

$\mathrm{C}=$ kebebasan samping $(0.9 \mathrm{~m})$

$\mathrm{C}=1 / 2 \mathrm{~B}-\mathrm{b}$

$\mathrm{C}=1 / 2(7)-2,6$ $\mathrm{C}=0,9$

$\mathrm{P}=$ jarak antara as roda depan dan belakang $(18,9 \mathrm{~m})$

$\mathrm{A}=$ jarak ujung mobil dan ban depan $(1,2 \mathrm{~m})$

$\mathrm{V}_{\mathrm{R}}=$ kecepatan rencana $(60 \mathrm{~km} / \mathrm{jam})$

$\mathrm{Rc}=$ jari-jari tikungan $(\mathrm{m})$

Rumus Lebar Pelebaran:

$$
W=B-L
$$

Dimana:

$\mathrm{B}=$ lebar total

$\mathrm{L}=$ lebar badan jalan $(2 \times 3,5 \mathrm{~m})$

\section{Perhitungan:}

1. $\mathrm{b}^{\prime \prime}=R-\left(\sqrt{R^{2}-P^{2}}\right)$

$$
\begin{gathered}
=179- \\
\left(\sqrt{179^{2}-18,9^{2}}\right) \\
=1 \mathrm{~m}
\end{gathered}
$$

2. $\mathrm{b}^{\prime}=2,6+1$

$$
=3,6 \mathrm{~m}
$$

3. $T_{d}=\sqrt{R^{2}+A(2 P+A)}-R$

$$
\begin{aligned}
& \quad= \\
& \sqrt{179^{2}+1,2(2 \times 18,9+1,2)}- \\
& 179
\end{aligned}
$$

$$
\text { 4. } \begin{aligned}
& \mathrm{Z}= 0,105 \times \frac{V r}{\sqrt{R C}} \\
&=0,105 \times \frac{60}{\sqrt{179}} \\
&=0.47 \mathrm{~m} \\
& \text { 5. } B \quad=n\left(b^{\prime}+c\right)+(n-1) T_{d}+ \\
& Z \quad 2(3,6+0.9)+(2- \\
& \text { 1) } 0.13+0.47 \\
&=9,6 \mathrm{~m}>7 \mathrm{~m} \\
& \mathrm{~W}=\mathrm{B}-\mathrm{L} \\
&=9,6-7 \\
&=2,6
\end{aligned}
$$

Karena $\mathrm{B}>\mathrm{W}$ maka diperlukan lebar perkerasan pada tikungan $\mathrm{PI}_{12}$ sebesar 2,6 m.

\section{g. Penghitungan kebebasan samping pada $\mathrm{PI}_{12}$}

Data-data:

$$
\begin{aligned}
& \mathrm{Vr}=60^{\mathrm{km} / \mathrm{jam}} \\
& \mathrm{Rc}=179 \mathrm{~m} \\
& \mathrm{~W}=2 \times 3,5 \mathrm{~m}=7 \mathrm{~m} \\
& \mathrm{Lc}=149,88 \mathrm{~m}
\end{aligned}
$$

- Jarak pandang henti $(\mathrm{Jh})=75 \mathrm{~m}$

- Jarak pandang menyiap (Jd) $=350 \mathrm{~m}$

- Lebar pengawasan minimal $=30 \mathrm{~m}$

Perhitungan :

$$
\begin{aligned}
\mathrm{R}^{\prime} & =\mathrm{Rc}-1 / 2 \mathrm{~W} \\
& =179-1 / 27 \\
& =175 \mathrm{~m} \\
\mathrm{Lt} & =\mathrm{Lc}+(2 \times \mathrm{Ls}) \\
& =149,88+(2 \times 50) \\
& =249,88 \mathrm{~m}
\end{aligned}
$$

a. Jarak pandang henti berdasarkan TPGJAK 1997:

$$
\begin{aligned}
\mathrm{Jh} & =0,694 \mathrm{Vr}+0,004\left[\mathrm{Vr}^{2} /(f p)\right] \\
& =0,694 \times 60+0,004 \times\left[60^{2} /(0,50)\right] \\
& =70,44 \mathrm{~m}
\end{aligned}
$$

b. Jarak pandang henti berdasarkan Shirley L.hendarsin

$f p=$ Koefisien gesek memanjang menurut

Bina Marga, $f \mathrm{p}=0.35-0.55$

$$
\begin{aligned}
\mathrm{Jh} & =0,278 \mathrm{~V} . \mathrm{t}+\frac{V^{2}}{254 f} \\
& =0,27860 \times 2,5+\frac{60^{2}}{254 \times 0,50} \\
& =70,04 \mathrm{~m}
\end{aligned}
$$

Diambil Jh terbesar $=70,44 \mathrm{~m}$

c. Berdasarkan jarak pandang menyiap

$$
\begin{aligned}
\mathrm{Jd} & =\mathrm{d}_{1}+\mathrm{d}_{2}+\mathrm{d}_{3}+\mathrm{d}_{4} \\
\mathrm{~d}_{1} & =0,278 \times T_{1} \times\left(V_{R}-\mathrm{m}+\frac{a \times T_{1}}{2}\right) \\
\mathrm{d}_{2} & =0,278 \times V_{R} \times T_{2}
\end{aligned}
$$




$$
\begin{array}{ll}
\mathrm{d}_{3} & =\text { antara } 30-100 \mathrm{~m} \\
\mathrm{~d}_{4} & =2 / 3 \mathrm{x} \mathrm{d}_{2}
\end{array}
$$

Dimana :

$\mathrm{T}_{1}=$ Waktu dalam (detik), $\infty 2.12+0,026 \times \mathrm{Vr}$

$\mathrm{T}_{2}=$ Waktu kendaraan berada di jalur lawan, (detik) 6,56+0,048xVr

A $=$ Percepatan rata-rata $\mathrm{km} / \mathrm{jam} / \mathrm{dtk}$, $(\mathrm{km} / \mathrm{jam} /$ detik $), 2,052+0,0036 \mathrm{xVr}$

$\mathrm{m}=$ perbedaan kecepatan dari kendaraan yang menyiap dan kendaraa yang di siap, (biasanya diambil 10-15 km/jam)

$$
\begin{aligned}
& \mathrm{T}_{1}=2.12+0,026 \times 60 \\
& =3,7 \\
& \mathrm{~T}_{2}=6,56+0,048 \times 60 \\
& =9,44 \\
& \mathrm{~A}=2,052+0,003 \times 60 \\
& =2,3 \\
& \mathrm{M}=15 \\
& \mathrm{~d}_{1}=0,278 \times T_{1} \times\left(V_{R}-\mathrm{m}+\frac{a \times T_{1}}{2}\right) \\
& =0,278 \times 3,7 \times\left(60-15+\frac{2,3 \times 3,7}{2}\right) \\
& =50,66 \mathrm{~m} \\
& \mathrm{~d}_{2} \quad=0,278 \times V_{R} \times T_{2} \\
& =0,278 \times 60 \times 9,44 \\
& =157,46 \mathrm{~m} \\
& \mathrm{~d}_{3}=\operatorname{antara} 30-100 \mathrm{~m} \\
& =30 \mathrm{~m} \\
& \mathrm{~d}_{4} \quad=2 / 3 \times \mathrm{d}_{2} \\
& =2 / 3 \times 157,46 \\
& \mathrm{Jd}=\mathrm{d}_{1}+\mathrm{d}_{2}+\mathrm{d}_{3}+\mathrm{d}_{4} \\
& \mathrm{Jd}=50,66+157,46+30+104,97 \\
& \mathrm{Jd}=343,09 \mathrm{~m}
\end{aligned}
$$

Jd terbesar diambil $=343,09$

Kebebasan samping yang tersedia

$$
\begin{aligned}
(\mathrm{mo}) & =1 / 2(\text { lebar pengawasan minimal }-\mathrm{w}) \\
& =1 / 2(30-7) \\
& =11,52 \mathrm{~m}
\end{aligned}
$$

Secara analitis :

- Berdasarkan jarak pandang henti :

$$
\begin{aligned}
& \mathrm{Jh}=70,44 \mathrm{~m} \\
& \mathrm{Lt}=249,88 \mathrm{~m} \mathrm{Jh}<\mathrm{Lt} \\
& \mathrm{E}=\mathrm{R}^{\prime} \times\left(1-\cos \times\left(\frac{28,65 \times \mathrm{Jh})}{R^{\prime}}\right)\right. \\
& \mathrm{E}=175 \times\left(1-\cos \times\left(\frac{28,65 \times 70,44)}{175}\right)\right. \\
& \mathrm{E}=3,53
\end{aligned}
$$

- $\quad$ Berdasarkan jarak pandang menyiap :

$$
\mathrm{Jd}=343,09
$$$$
\mathrm{Lt}=249,88
$$$$
\mathrm{Jd}>\mathrm{Lt}
$$

$\mathrm{E}=\mathrm{R}^{\prime} \mathrm{x}\left(1-\cos \mathrm{x}\left(\frac{28,65 x \mathrm{Jd})}{R^{\prime}}\right)+\frac{(J d-L t)}{2} \mathrm{x} \sin (\right.$

$$
\begin{aligned}
& \left.\frac{28,65 \times \mathrm{Jd})}{R^{\prime}}\right) \\
& =175 \times\left(1-\cos \times\left(\frac{28,65 \times 343,09)}{175}\right)+\right. \\
& \frac{(343,09-249,88)}{2} \times \sin \left(\frac{28,65 \times 249,88)}{175}\right)
\end{aligned}
$$

$$
=108,08 \mathrm{~m}
$$

Rekapitulasi perhitungan :

1. Kebebasan samping henti $=3,53 \mathrm{~m}$

2. Kebebasan samping menyiap $=108,08 \mathrm{~m}$

3. Kebebasan samping tersedia $=11,52 \mathrm{~m}$

4. Kebebasan samping berdasarkan jarak pandang henti 3,53 $\mathrm{m}<11,52 \mathrm{~m}$ sehingga aman

5. Kebebasan samping berdasarkan jarak pandang menyiap 108,08 m > 11,52 m sehingga sebelum memasuki tikungan $\mathrm{PI}_{2}$ perlu dipasang rambu dilarang menyiap.

\section{h. Perkerasan Lentur}

1. Data Perencanaan Tebal Perkerasan

Tebal perkerasan untuk 1 jalur 2 lajur 2 arah (2/2 UD), Jalan yang direncanakan adalah jalan Arteri, Umur rencana jalan $=10$ tahun Angka pertumbuhan lalu lintas $=5 \%$ per tahun. Curah hujan rata-rata $=1438 \mathrm{~mm} /$ tahun Kelandaian jalan $=11,53 \%$

CBR tanah dasar $=4,0 \%$

2. Susunan lapis perkerasan

- Lapisan permukaan (Surface Course) = (LASTON MS $744 \mathrm{Kg}$ )

- Lapisan Pondasi Atas (Base Course) $=($ Batu Pecah CBR 100\% )

- Lapisan Pondasi Bawah (Sub Base Course) = (SIRTU CBR 50\% )

3. Data hasil survey lalu lintas :

- Kendaraan ringan 2 ton $(1+1)$

$4051 \mathrm{kend} / \mathrm{hari}$

- Bus Kecil 4 ton $(2+2)$

$34 \mathrm{kend} / \mathrm{hari}$

- Bus Besar 8 ton $(3+5)$

- Truk 2 As 8 ton $(3+5)$

- Truk 2 As 13 ton $(5+8)$

$76 \mathrm{kend} / \mathrm{hari}$

$57 \mathrm{kend} / \mathrm{hari}$

$16 \mathrm{kend} / \mathrm{hari}$ i. Perhitungan LHR awal dan LHR $_{\text {akhir }}$

a. LHR pada akhir umur rencana (tahun ke-10) : $\mathrm{LHR}_{\mathrm{akhir}}=\mathrm{LHR}_{\mathrm{awal}}(1+$ tingkat pertumbuhan kendaraan) $^{\mathrm{UR}}$

- Kendaraan ringan 2 ton

$$
\begin{aligned}
& (1+1)=4051 \\
& (1+5 \%)^{10}=6599 \text { kend/hari }
\end{aligned}
$$

- Bus Kecil 4 ton $(2+2)=34 \quad(1+5 \%)^{10}=56 \mathrm{kend} /$ hari

- Bus Besar 8 ton

$$
(3+5)=76
$$

$(1+5 \%)^{10}=124 \mathrm{kend} / \mathrm{hari}$ 
- Truk 2 As 8 ton $(3+5)=57 \quad(1+5 \%)^{10}=93 \quad \mathrm{kend} / \mathrm{hari}$

- Truk 2 As 13 ton $(5+8)=16(1+5 \%)^{10}=27 \quad \mathrm{kend} / \mathrm{hari}$

b. Menghitung angka ekivalen (E) masing-masing kendaraan (tabel 2.14)

- Kendaraan ringan 2 ton $(1+1) \quad 0,0002+0,0002=0,0004$

- Bus kecil 4 ton $(2+2) 0,0036+0,0036=0,0072$

- Bus Besar 8 ton $(3+5) \quad 0,0183+0,1410=0,1593$

- Truk 2 As 8 ton $(3+5) \quad 0,0183+0,1410=0,1593$

- Truk 2 As 13 ton $(5+8) \quad 0,1410+0,9238=1,0648$

c. Menghitung lintas ekivalen permulaan LEP $=\sum$ LHR x C x E

Nilai $C$ di dapat dari tabel 2.13 koefisien distribusi kendaraan (C)

- Kendaraan ringan 2 ton $(1+1)=4051 \times 1 \times 0,0004=1,6204$

- Bus Kecil 4 ton $(2+2)=34 \times 1 \times 0,0072=0,2448$

- Bus Besar 8 ton $(3+5)=76 \times 1 \times 0,1593=12,1068$

- Truk 2 As 8 ton $(3+5)=57 \times 1 \times 0,1593=9,0801$

- Truk 2 As 13 ton $(5+8)=16 \times 1 \times 1,0648=17,0368$ $\sum$ LEP $=$ 40,0889

d. Menghitung lintas ekivalen akhir $\mathrm{LEA}=\sum \mathrm{LHR}_{\text {akhir }} \mathrm{x} \mathrm{C} \times \mathrm{E}$

- Kendaraan ringan 2 ton $(1+1)=6599 \times 1 \times 0,0004=2,6396$

- Bus Kecil 4 ton

- $(2+2)=56 \times 1 \times 0,0072=0,4032$

- Bus Besar 8 ton $(3+5)=124 \times 1 \times 0,1593=19,7532$

- Truk 2 As 8 ton $(3+5)=93 \times 1 \times 0,1593=14,8149$

- Truk 2 As 13 ton $(5+8)=27 \times 1 \times 1,0648=28,7496$

$$
\sum \text { LEA }=66,3605
$$

e. Menghitung lintas ekivalen tengah

$$
\begin{aligned}
& \text { LET }=1 / 2(\text { LEP }+ \text { LEA }) \\
& \text { LET }=1 / 2(40,0889+66,3605) \\
& \text { LET }=53,2247
\end{aligned}
$$

f. Menghitung lintas ekivalen umur rencana

$\mathrm{LER}=\mathrm{LET} \times \mathrm{x}$ UR $/ 10$

LER $=53,2247 \times 10 / 10$

$\mathrm{LER}=53,2247$
$\mathrm{LER} \approx 53$

\section{j. Perencanaan Perkerasan Lentur}

1. Data Perencanaan Tebal Perkerasan

Tebal perkerasan untuk 1 jalur 2 lajur 2 arah (2/2 UD)

Jalan yang direncanakan adalah jalan Arteri Umur rencana jalan $=10$ tahun

Angka pertumbuhan lalu lintas $=5 \%$ per tahun.

Curah hujan rata-rata $=1438 \mathrm{~mm} / \mathrm{thn}$

Kelandaian jalan $=11,53 \%$

CBR tanah dasar $=4,0 \%$

2. Data

LHR $=4234 \mathrm{kend} / \mathrm{hari}$

Susunan lapis perkerasan

- Lapisan permukaan (Surface Course)

$=($ LASTON MS $744 \mathrm{Kg})$

- Lapisan Pondasi Atas (Base Course)

$=($ Batu Pecah CBR 100\% $)$

- Lapisan Pondasi Bawah (Sub Base Course) $=($ SIRTU CBR $50 \%)$

- Untuk CBR Tanah dasar 4,0 \%

$\mathrm{DDT}=4,3 \log (\mathrm{CBR}=4)+1,7$ diperoleh $\mathrm{DDT}=$ 4,29

\section{Penentuan Tebal Lapis Perkerasan}

Dengan DDT $=4,29, \mathrm{LER}=53, \mathrm{FR}=2,5$

maka diperoleh ITP $=7,6$

$>$ Lapisan permukaan (Surface Course) $=($ LASTON MS $744 \mathrm{Kg}) \mathrm{a}_{1}=0,40$

$>$ Lapisan Pondasi Atas (Base Course) $=($ Batu Pecah CBR 100\% $) a_{2}=0,14$

$>$ Lapisan Pondasi Bawah (Sub Base Course) $=($ SIRTU CBR 50\% $) \mathrm{a}_{3}=0,12$

$>$ Tebal minimum perkerasan untuk ITP $=7,6$ diperoleh :

- Lapis permukaan LASTON $\left(\mathrm{D}_{1 \mathrm{~min}}\right)$

- Lapis Permukaan AC-WC $=4 \mathrm{~cm}$

- Lapis Permukaan AC-BC $=6 \mathrm{~cm}$

- LPA dari batu pecah $\left(\mathrm{D}_{2 \min }\right)=20 \mathrm{~cm}$

- LPB untuk setiap nilai ITP $\left(\mathrm{D}_{3 \mathrm{~min}}\right)=10 \mathrm{~cm}$ Menetapkan Tebal Lapis Perkerasan

$\mathrm{ITP}=\mathrm{a}_{1} \cdot \mathrm{D}_{1}+\mathrm{a}_{2} \cdot \mathrm{D}_{2}+\mathrm{a}_{3} \cdot \mathrm{D}_{3}$

$7,6=(0,40)\left(\mathrm{D}_{1}\right)+(0,14)(20)+(0,12)(10)$

$\mathrm{D}_{1}=[7,6-(2,8+1,2)] / 0,40$

$\mathrm{D}_{1}=9 \mathrm{~cm}$ ini $<\mathrm{D}_{1 \mathrm{~min}}=10 \mathrm{~cm}$, sehingga diambil $\mathrm{D}_{1}=10 \mathrm{~cm}$

Susunan Perkerasan menjadi :

- $\quad$ LASTON $($ MS $744 \mathrm{~kg})=10 \mathrm{~cm}$

- Lapis permukaan $\mathrm{AC}-\mathrm{WC}=4 \mathrm{~cm}$

- Lapis permukaan $\mathrm{AC}-\mathrm{BC}=6 \mathrm{~cm}$

- Batu Pecah Kelas B (CBR 80\%) $=20 \mathrm{~cm}$ 
- Sirtu Kelas C (CBR 30\%) $=10 \mathrm{~cm}$

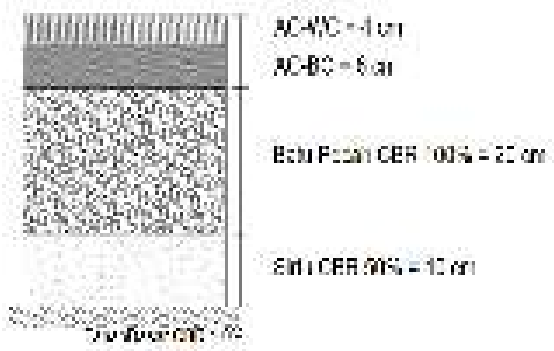

Gambar 7. Perencanaan Susunan Perkerasan jalan

\section{k. Rekapitulasi Rencana Anggaran Biaya}

Tabel 1. Perhitungan rencana Anggaran Biaya

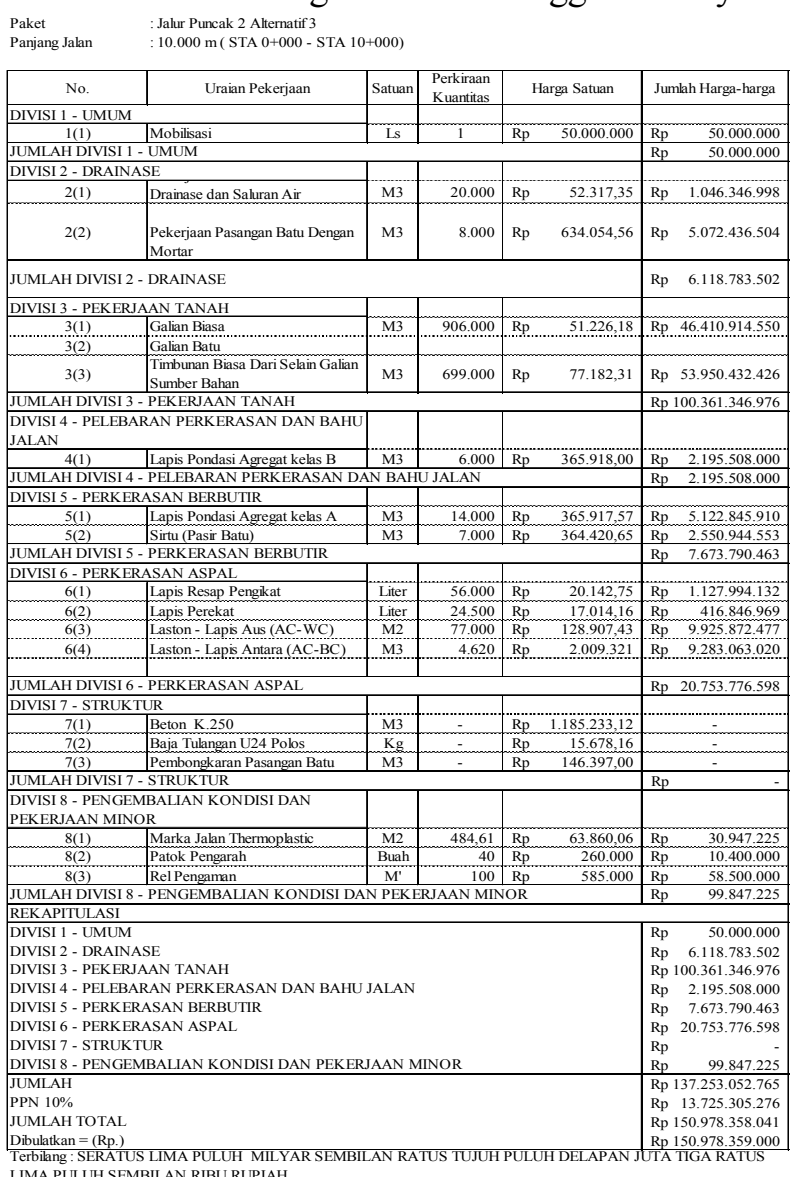

LIMA PULUH SEMBILAN RIBU RUPIAH

\section{KESIMPULAN}

Dari hasil perencanaan geometrik dan tebal perkerasan pada rencana Jalan Jalur Puncak 2 alternatif III dapat disimpulkan bahwa:

1. Jalan Jalur Puncak 2 alternatif III merupakan jalan Arteri ( Kelas I ) dengan tipe jalan 1 jalur 2 lajur 2 arah (2/2 UD), panjang jalan $10 \mathrm{~km}$, lebar perkerasan $7 \mathrm{~m}$, kelas medan jalan merupakan daerah perbukitan dengan kecepatan rencana $60 \mathrm{~km} / \mathrm{jam}$.

2. Perencanaan alinemen horizontal direncanakan jenis tikungan dengan lengkung peralihan Spiral-Circle-Spiral (SCS).

3. Untuk perencanaan tebal perkerasan jalan pada trase jalan ini penulis merencanakan dengan Perkerasan Lentur. Hasil perhitungan di sajikan dalam tabel yaitu sebagai berikut

\begin{tabular}{|c|c|c|c|c|c|c|c|c|}
\hline $\begin{array}{c}\text { Umur } \\
\text { Rencana }\end{array}$ & DDT & LER & FR & Ipt & Ipo & ITP & \multicolumn{2}{|c|}{ Tebal Perkerasan } \\
\hline 10 Tahun & 4,29 & 53 & 2,5 & 2 & $\begin{array}{c}\text { LASTON (MS } 744 \\
\text { KG) } 3,9-3,5\end{array}$ & 7,6 & $10 \mathrm{~cm}$ & $20 \mathrm{~cm} / 10 \mathrm{~cm}$ \\
\hline
\end{tabular}

4. Anggaran Biaya yang dibutuhkan untuk pembangunan Jalan Jalur Puncak 2 Alternatif III sebesar Rp.150.978.359.000.00 (seratus lima puluh milyar sembilan ratus tujuh

\section{DAFTAR PUSTAKA}

Departemen Pekerjaan Umum Direktorat Jenderal Bina Marga Jalan No.038/T/BM/1997, Tatacara Perencanaan Geometrik Jalan Antar Kota. Badan Penerbit Pekerjaan Umum. Jakarta: 1997.

Departemen Pekerjaan Umum Direktorat Jenderal Bina marga, Petunjuk Perencanaan Tebal Perkerasan Lentur Jalan Raya Dengan Analisa Komponen. Badan Penerbit Pekerjaan Umum. Jakarta: 1989.

Silvia, Sukirman, Dasar-Dasar Perencanaan Geometrik Jalan, Nova. Bandung: 1995.

Saodang, Hamirhan, Konstruksi Jalan Raya, Nova. Bandung : 2004. 